\title{
Modulation of Locomotor Patterns and Spasticity with Clonidine in Spinal Cord Injured Patients
}

\author{
J.E. Stewart, H. Barbeau and S. Gauthier
}

\begin{abstract}
This double blind cross-over study, involving 9 chronic spinal cord injured (SCI) patients (6 paraplegic and 3 paretic), was a first attempt to investigate the effects of the noradrenergic agonist, clonidine, on the modulation of the locomotor pattern and spasticity in patients with spinal cord lesions. Electromyographic (EMG), footswitch and video recordings were made as the patients walked on a treadmill with the support of an overhead harness if needed. Overground locomotion was also assessed in the paretic patients. All 3 spastic paretic patients had kinematic deviations and abnormal EMG recruitment profiles during the premedication or placebo sessions. With clonidine therapy one patient demonstrated a marked improvement in locomotor function. This patient progressed from non-ambulation to limited independent ambulation as the extent of coactivation in antogonist muscles decreased. The other 2 paretics who presented limited spasticity showed minimal changes while on clonidine. In the paraplegic patients, clonidine did not elicit locomotor activity, although there were marked reductions in stretch reactions and clonus during assisted locomotion. They remained incapable of locomotion, either during the control period or during the clonidine therapy. These results indicate that clonidine may be a potentially useful medication for both locomotion and certain manifestations of spasticity in SCI patients but further investigation is warranted.
\end{abstract}

RÉSUMÉ: Modulation des patrons locomoteurs et de la spasticité par la clonidine chez les traumatisés médullaires. Cette étude à double insue avait pour but d'étudier les effets de la clonidine, un agoniste noradrénerigique, sur la fonction locomotrice et la spasticité chez 9 patients (6 patients paraplégiques et 3 patients parésiques) ayant une lésion de la moelle épinière. Des enregistrements électromyographiques et cinématographiques furent effectués durant la marche sur un tapis roulant, avec l'aide d'un harnais lorsque nécessaire. La marche au sol fut aussi évaluée chez les trois patients parésiques spastiques. Ceux-ci présentèrent tous des patrons cinématiques et électromyographiques anormaux pendant la période contrôle ou placebo. Suite à l'administration de la clonidine, un des trois patients parésiques spastiques montra une nette amélioration de la fonction locomotrice, progressant d'un stade non-ambulatoire à une ambulation indépendante limitée. Une diminution de la coactivation musculaire fut aussi notée. Les 2 autres patients parésiques, présentant au départ une spasticité limitée, montrèrent des changements légers durant la période avec clonidine. Chez les patients paraplégiques, la clonidine n'a pas induit d'activité locomotrice, bien qu'il y eut une réduction des réflexes d'étirements et du clonus durant la locomotion assistée. Ceux-ci furent incapables de marcher, autant durant la période contrôle que durant la période avec clonidine. Ces résultats préliminaires indiquent que la clonidine peut être un médicament potentiellement utile pour améliorer la fonction locomotion et diminuer certaines mainifestations de la spasticité chez les patients ayant une lésion de la moelle épinière, mais d'autres études sont nécessaires.

Can. J. Neurol. Sci. 1991; 18:321-332

Spastic paretic gait has been distinguished from normal gait by an alteration in the timing, duration, profile and variability of EMG activity ', deviation in joint kinematics, as well as prolongation of both the stance phase and total double support duration. ${ }^{2,3}$ The difficulty in coping with increased speed and weight bearing with the affected lower extremities has also been reported in spastic paretics. 4,5 These problems may be associated with hyperactive stretch reflexes evoked as the muscles contract, 5 as well as hypertonia, clonus and various degrees of paresis. ${ }^{6-8}$

A treatment strategy which could address some of these problems would be of considerable benefit to this patient population. Recent clinical trials have explored the antispastic effects of the noradrenergic alpha agonist clonidine in spinal cord injured patients. Clonidine reportedly decreased muscular

From the School of Physical and Occupational Therapy, McGill University, Montreal

Received June 15, 1990. Accepted in final form January 5, 1991

Reprint requests to: Hugues Barbeau, Ph.D., School of Physical and Occupational Therapy, McGill University, 3654 Drummond Street, Montreal, Quebec, Canada H3G 1 Y 5 
hypertonus, ${ }^{9-11}$ spontaneous spasms 9,11 and, to a lesser extent, clonus. ${ }^{10}$ However, these clinical studies did not directly address functional motor activities such as locomotion.

The effect of clonidine in modulating locomotion and spinal reflexes was recently investigated in the chronic spinal cat (CSC) in which all the monoaminergic terminals below the transection have degenerated. ${ }^{12,13}$ Briefly, clonidine markedly modified the locomotor pattern of the CSC by increasing the step cycle duration as well as the flexor and extensor burst durations, associated with an increase in the angular excursion of all joints. ${ }^{12,13}$ Moreover, clonidine has also been found to induce locomotion in the early period of recovery following spinalization. ${ }^{13-15}$ These modulatory effects are thought to reflect the action of clonidine on the spinal neuronal circuitry hypothesized to organize the motor pattern for locomotion. ${ }^{16}$

In light of the above findings, the purpose of this study was to investigate the possible modulatory effects of clonidine on locomotor function and spasticity in patients with chronic spinal cord lesions. Preliminary results have been published in abstract form. 17

\section{Methodology}

\section{Subjects}

Table 1 summarizes the demographic data for the participants in this study. Six of the nine patients who completed the study had lesions of traumatic origin. Two patients, $P_{2}$ and $P_{6}$, developed the lesion secondary to surgery for cancer, and $P_{9}$ had been paralyzed for 5 years due to progressive kyphoscoliosis. The lesion chronicity ranged from 1 to 10 years. All patients were discharged from the rehabilitation centre and were stabilized on other antispasmodic medications. In total, six patients had minimal or no sensation and no motor function below the lesion site (Frankel category A and B), two had incomplete sensation and some useful motor function (Frankel category D), the one had incomplete sensation and no useful motor function (Frankel category C) ${ }^{18}$ in association with marked spasticity. For the purpose of this study, patients in categories C and D will be referred to as paretics, due to the possibility of residual motor function; those in category $\mathrm{A}$ and $\mathrm{B}$ will be referred to as paraplegics, due to the lack of motor function below the level of the lesion. The three patients who did not complete the study withdrew for reasons of illness or inability to comply with the protocol.

\section{Clonidine Administration}

This double-blind crossover study involved 2 periods of 4 weeks of medication separated by a 2 week washout period. The order of clonidine and placebo was randomly assigned. Clonidine and placebo were administered orally 2 or 3 times per day. The concentration per tablet was $0.025 \mathrm{mg}$. The initial daily dosage was $0.05 \mathrm{mg} /$ day and was systematically increased to an optimal level that was maintained for two weeks prior to the assessment session. The optimal dosage level was defined as the maximum level of medication within the titration range which caused minimal adverse side-effects. The titration protocol was

\begin{tabular}{|c|c|c|c|c|c|c|}
\hline Name & $\begin{array}{c}\text { Age } \\
(\mathrm{yrs})\end{array}$ & Sex & $\begin{array}{l}\text { Lesion } \\
\text { Level }\end{array}$ & $\begin{array}{c}\text { Lesion } \\
\text { Chronicity } \\
\text { (yrs) }\end{array}$ & $\begin{array}{c}\text { Daily } \\
\text { Dosage } \\
\text { (mg) }\end{array}$ & $\begin{array}{c}\text { Frankels } \\
\text { Categories } \\
\text { (A-D) }\end{array}$ \\
\hline$P_{1}$ & 25 & $\mathrm{M}$ & T4 & 2 & 0.20 & $\mathrm{D}$ \\
\hline $\mathrm{P}_{2}$ & 33 & M & $\mathrm{T} 10$ & 4 & 0.20 & $\mathrm{D}$ \\
\hline $\mathrm{P} 3$ & 24 & M & $\mathrm{C} 7-\mathrm{T} 1$ & 1 & 0.50 & $\mathrm{C}$ \\
\hline$P_{4}$ & 22 & $\mathrm{M}$ & $\mathrm{T7}$ & 1. & 0.20 & $\mathrm{~A} / \mathrm{B}$ \\
\hline$P_{5}$ & 42 & $\mathbf{M}$ & TS- 6 & 10 & 0.25 & $\mathrm{~A} / \mathrm{B}$ \\
\hline $\mathrm{P}_{6}$ & 19 & $\mathbf{M}$ & T9-10 & 1 & 0.15 & $\mathrm{~A} / \mathrm{B}$ \\
\hline$P_{7}$ & 26 & $M$ & $\mathrm{~T} 7$ & 2 & 0.15 & $\mathrm{~A} / \mathrm{B}$ \\
\hline $\mathrm{P}_{8}$ & 25 & M & $\mathrm{T} 7$ & 1 & 0.20 & $\mathrm{~A} / \mathrm{B}$ \\
\hline $\mathrm{P}_{9}$ & 37 & $\mathbf{M}$ & C7-TI & 5 & 0.10 & $\mathrm{~A} / \mathrm{B}$ \\
\hline \multicolumn{7}{|c|}{ Withdrawn: } \\
\hline$P_{10}$ & 45 & $\mathbf{M}$ & T8-10 & 14 & - & $\mathrm{A} / \mathrm{B}$ \\
\hline$P_{11}$ & 37 & $\mathbf{M}$ & T8-9 & 20 & - & $\mathrm{A} / \mathrm{B}$ \\
\hline$P_{12}$ & 57 & M & T11 & 2 & - & $\mathrm{D}$ \\
\hline
\end{tabular}

Demographic details of the patients. $P_{2}$ and $P_{6}$ : Lesion secondary to surgery for cancer, $P_{9}$ Kyphoscoliosis resulting in progressive paralysis; 6 other patients $=$ fall or motor vehicle accident resulting in SCI. Frankel's classifications: A: No sensation and no motor function below lesion; B: Minimal sensation and no motor function below lesion; $\mathrm{C}$ : incomplete sensation, no motor function below lesion; D: incomplete sensation, useful motor function below lesion. 
developed in collaboration with the Boerhinger Ingelheim Co., to establish an optimal dose level within the range of $0.05-0.25$ $\mathrm{mg}$ and below the range normally prescribed for antihypertensive effects. All of the patients were stabilized within this range except $P_{3}$, who independently raised his daily dosage level to $0.50 \mathrm{mg}$ despite instructions. Since $P_{1}$ was a preliminary subject, the placebo medication was not given and thus the results were taken from a pre-medication session and a post-clonidine session. To maintain the double-blind design, the titration procedures for the placebo and the clonidine were identical, as was the appearance of the tablets. The three patients on other drugs such as baclofen were stabilized for a month before the beginning of the present study.

Since the blood plasma level of clonidine peaks within 1-3 hours following oral administration, ${ }^{19,20}$ each patient's vital signs were monitored for possible side effects over two hours following the initial dose. Subsequently, the medication was increased every 3 days following a visit from a public health nurse who, blind to the medication type, assessed vital signs and examined the patient for signs of adverse side-effects using a standardized form. Dosage was increased or decreased by increments of $0.05 \mathrm{mg}$.

\section{Assessment of Locomotion}

Following an initial orientation session, assessment sessions were given preceding and following each medication period to evaluate treadmill and overground locomotion, as well as clinical spasticity, including tonic stretch reflex of the ankle and knee, ankle clonus, and measurement of the patient's perceived level of spasticity using a visual analog scale. These evaluations were undertaken mainly during the morning at the time of the near-maximal effect of clonidine. Patients walked on a motordriven treadmill, while comfortably supported by a custom-built overhead harness, if required. The harness was part of a system that estimated the percentage of weight supported by the patient, and has been previously described. ${ }^{21}$ The system was utilized to provide body weight support (BWS) as required for those patients who could not walk with full weight bearing. The BWS system was used to lift the paraplegic patients from the wheelchair to the standing position, and to support their weight during assisted locomotion. All patients walked on the treadmill at the minimal speed of $0.26 \mathrm{~ms}^{-1}$, with research assistants manually advancing the legs of all paraplegic patients to simulate walking.

Surface EMG, footswitch and video recordings were made during treadmill and overground locomotion to obtain EMG, kinematic and foot placement data. Bipolar surface EMG electrodes were used to detect the activity of the following lower limb muscles: right gluteus maximus (GM), right and left medial hamstrings $(\mathrm{MH})$, vastus lateralis (VL), tibialis anterior (TA), and the medial head of gastrocnemius (GA). Signals were differentially amplified and bandpassed at $10-470 \mathrm{~Hz}$. EMG and footswitch recordings were displayed on an oscilloscope and recorded by a 14-channel FM tape recorder at 3.75 i.p.s. (frequency response $0-2500 \mathrm{~Hz}$ ). Additionally, comments were recorded on an audio channel of both the FM and video tapes. A time code was also recorded on both tapes to synchronize the video and EMG data.

Raw signals were digitized at $1 \mathrm{KHz}$ and stored on computer. Subsequent computer analysis was performed on temporal aspects of the muscle activity, as well as on the EMG activation profile. Ten consecutive and representative cycles of data were normalized to the gait cycle duration, defined as the time between one foot-floor contact (FFC) and the subsequent FFC of the same foot, for between-session comparisons. To assess gait kinematics, reflective markers were attached to landmarks at the shoulder, hip, knee, and ankle joints as well as along the foot. Movements of the patients' lower extremities in the sagittal plane were videotaped with a rotary shutter video camera and recorded at 60 fields $/ \mathrm{sec}$. The angular excursions of the hip, knee, and ankle were subsequently measured directly from the video monitor using a goniometer at intervals of $5 \%$ of a representative step cycle. Velocity, cadence, and stride lengths were also determined as the paraparetics walked overground between parallel bars 8 feet in length.

\section{Assessment of Spasticity}

The clinical assessment of spasticity included a visual analog scale measure of the subjective perception of spasticity, and an objective evaluation of the tonic stretch reflex and evoked ankle clonus. Additionally, all patients were asked to keep a daily diary of spasms and clonus, a task with which four and seven complied, respectively.

Using the visual analog scale, the patients were asked to rate spasticity referenced to the most severe spasticity they had experienced. On one side of the scale no numerical values were visible between 2 extreme reference points, while on the examiner's side the scale was numbered from 0 to 10 . Thus, the patient's subjective response corresponded to numerical values for the examiner (0: no spasticity to 10: maximum spasticity).

To evaluate tonic stretch reflex, the right and left ankles were gradually dorsiflexed in a relatively constant time by the examiner. This test was conducted first with the knee in extension $\left(0^{\circ}\right)$, and then repeated with the knee in flexion $\left(90^{\circ}\right)$. In both cases, the resistance to passive movement was recorded on a 5point scale (0: normal resistance, 1: minimal, 2: moderate, 3 : strong, and 4: maximal resistance). Passive flexion and extension of the knee was also conducted. To test for ankle clonus, the patient was seated with the hip and knee flexed at $90^{\circ}$. Responses were graded using a 4 point scale ( 0 : no clonus, 1 : one to five beats, 2: five to ten beats; 3 : sustained clonus). To determine if the degree of spasticity had improved or deteriorated, comparisons of clonus, tonic stretch and visual analog scale measure were made between the placebo and the clonidine sessions for all patients. A change of at least 1 point (Tonic Stretch Reflex: $20 \%$, Visual Analog Scale: $10 \%$, clonus: $25 \%$ ) was considered a significant improvement or deterioration in the results of the spasticity tests.

\section{Results}

\section{The Effects of Clonidine on the Locomotor Pattern}

\section{Paretic Patients}

Each of the three paraparetic patients $\left(P_{1}, P_{2}\right.$ and $\left.P_{3}\right)$ demonstrated different locomotor capabilities at the onset of the study. The most severely spastic patient $P_{3}$ could only take 2 laborious assisted steps within a 4 minute period. Standing posture for $P_{3}$ was characterized by hip adduction, knee extension, and ankle plantarflexion, which resulted in toe-standing (Figure $1 \mathrm{~A}-\mathrm{D}$ ). A marked weight-bearing through the hands occurred, as evi- 


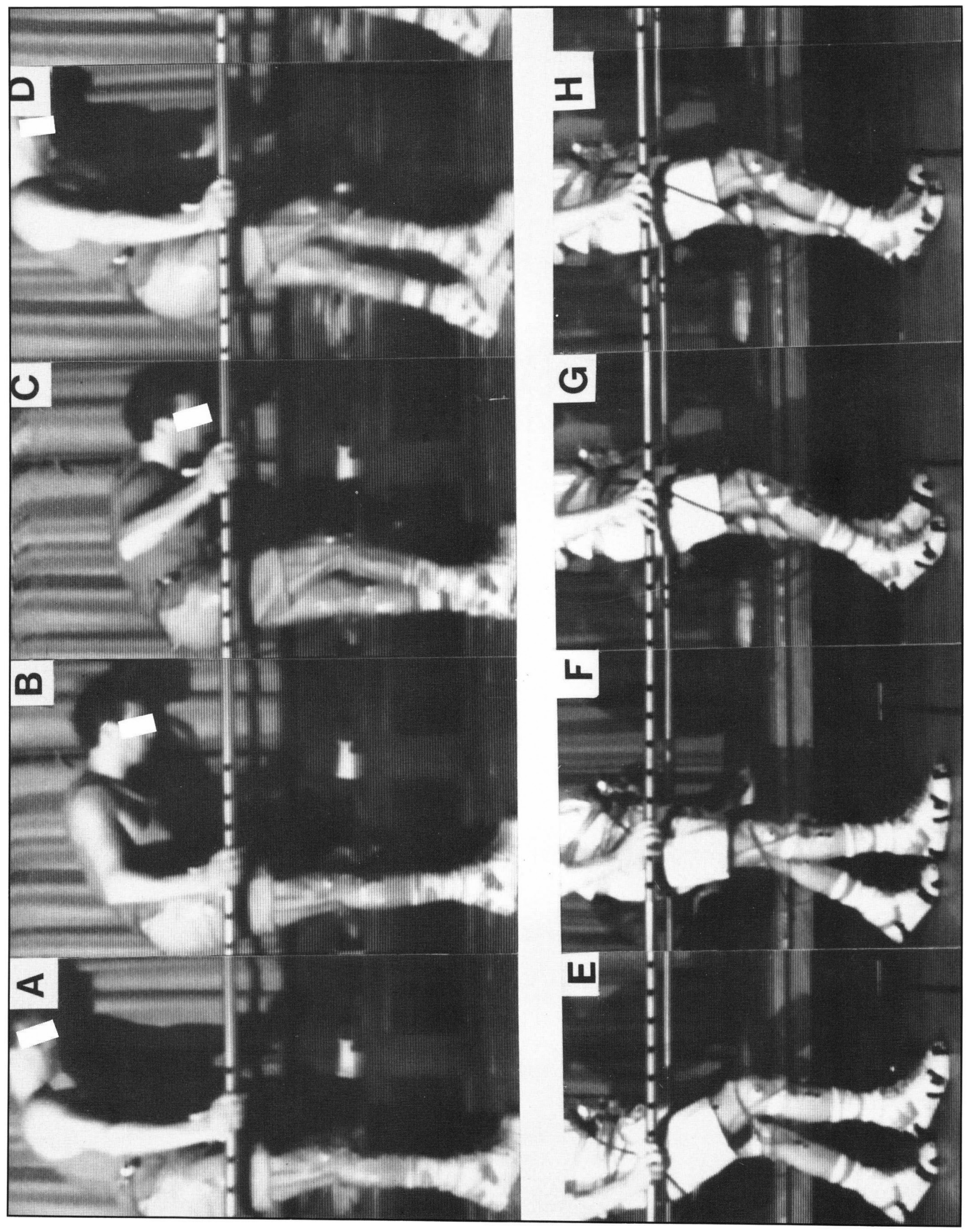


denced in Figure 1 by the tightly fisted hands (Figure 1 A-D). To initiate the first step, $P_{3}$ characteristically used a series of flexion manoeuvers of the trunk (Figure I A-D). This pattern was related to the marked extensor posture in the legs which $\mathrm{P}_{3}$ could only relax by assuming extreme trunk flexion.

With clonidine, a marked modification in locomotor function was noted, such that $P_{3}$ no longer utilized a trunk flexion strategy, demonstrating instead a more erect trunk posture while walking (Figure $1 \mathrm{E}-\mathrm{H}$ ). He showed reduced weight-bearing through the upper extremities, as suggested by the relaxed position of his hands (Figure 1 G-H). Kinematically, the hip (Figure $2 \mathrm{~A}$ ), knee (Figure $2 \mathrm{~B}$ ) and ankle (Figure $2 \mathrm{C}$ ) angular displacements were characterized by a gradual increase in flexion across the gait cycle while on placebo. During clonidine therapy, both the hip and knee joints moved into progressive extension during stance, followed by a reversal into flexion during the swing phase (Figure 2D and 2E). The total angular excursion of the hip increased (placebo: $10^{\circ}$ to $30^{\circ}$, clonidine: $-4^{\circ}$ to $30^{\circ}$ ), due to an increase in extension range during stance. However, the total angular excursion of the knee did not change (placebo: $15^{\circ}$ to $46^{\circ}$, clonidine: $12^{\circ}$ to $44^{\circ}$ ), and excessive knee flexion at footfloor contact (FFC) persisted. Ankle plantarflexion at FFC also remained, however this was followed by a more normal profile, with more dorsiflexion through early/mid stance, and plantarflexion following TO (Figure $2 \mathrm{~F}$ ). The total angular excursion was decreased for the ankle (placebo: $-15^{\circ}$ to $13^{\circ}$, clonidine: $-15^{\circ}$ to $3^{\circ}$ ). The footswitch recordings of foot-floor contact also indicated that the locomotor pattern was more consistent during the clonidine period. (Figure 3 ).

During the placebo period, the EMG pattern was characterized by a marked coactivation between antagonistic muscles (Figure 3), such that all muscles were co-activating throughout the step cycle except during the mid-swing period. Thus marked coactivation pattern of lower muscles during the placebo period (Figure 3) was replaced by a better phasic activation during the clonidine period (Figure 3). The muscles, GM, VL, and GA, were tonically active from late swing through stance to toe-off (TO). TA had an unusual activation profile, being active from mid to late stance with a second burst smaller in duration and amplitude at the beginning of the swing phase.

In contrast to $P_{3}, P_{1}$ and $P_{2}$ could walk independently either overground or on the treadmill at FWB, during the pre-medication or the placebo session, if provided with a Klenzac brace (left leg) to prevent foot dragging.

These two patients showed minimal changes following administration of clonidine (not illustrated). Table 2 summarizes data for cadence and stride lengths for overground locomotion, during administration of the placebo and clonidine in the 3 paretic patients. As $\mathrm{P}_{3}$ was unable to take consecutive steps during administration of the placebo and could not walk independently on the treadmill, only overground temporal distance val-

Figure $I$ - Paraparetic $P_{3}$ walking overground during placebo (upper row) and clonidine (lower row) sessions. Shown are foot floor contact $(A$ and $E)$, midstance ( $B$ and $F)$, toe-off ( $C$ and $G$ ), midswing $(D$ and $H)$. Note the changes in the trunk posture as well as the hands, hip, knee and ankle positions between the two sessions. ues during administration of clonidine are included. There were no significant modifications in cadence or stride length in overground locomotion for $\mathrm{P}_{1}$ and $\mathrm{P}_{2}$.

\section{Paraplegic Patients}

While on placebo, none of the paraplegic patients were able to initiate independent stepping. Rather, each patient was assisted in stepping passively on the treadmill while completely supported by the harness. Figure 4 provides an example of the marked tonic activity in all lower limb muscles of $P_{8}$ as the research assistant let go of his right leg and instructed him to attempt stepping. As indicated by the footswitch signal, the rhythmically phasic VL and MH burst activity observed during the assisted locomotion was replaced by tonic activation concomitant with dragging of the lower limb on the moving treadmill belt when the assistance stopped.

Another example of regular $\mathrm{MH}$ bursts is evident in Figure $5 \mathrm{~A}$, during assisted locomotion in the placebo session of $\mathrm{P}_{6}$. Right and left $\mathrm{MH}$ slowed a consistent alternating pattern (Figure 5A). The timing of this burst was coincident with the stretch applied to the hamstrings in mid-and late swing, when the knee was passively extended as the leg was drawn forward by the research assistants in preparation for foot-floor contact. Similarly, passive flexion and extension of the knee, with the same patient seated, consistently evoked an MH burst following administration of the placebo (Figure 5C). However, during the clonidine session, both stretch reactions were abolished (Figures 5B \& D). Furthermore, during assisted locomotion while on clonidine, the research assistants reported a reduction in the resistance previously felt when pulling the leg forward. This reduction in stretch reactions in $\mathrm{MH}$ during locomotion as demonstrated in $4 / 6$ patients $\left(P_{4}, P_{5}, P_{6}\right.$ and $\left.P_{8}\right)$ on clonidine.

The regular EMG bursts in records for $\mathrm{P}_{8}$, as well as the clonic discharge in the TA and GA muscles, were characteristically seen in most paraplegic subjects during assisted locomotion. Figure 6A illustrates clonic activation in TA and GA which was evoked during assisted locomotion in $\mathrm{P}_{8}$ while on placebo. The clonus began at foot-floor contact, and persisted until the early swing phase as the muscles were unloaded. Following administration of clonidine, the clonus was reduced to 2 beats or less (Figure 6B). Similarly, when tested at rest, in sitting, sustained clonus was evoked in $\mathrm{P}_{8}$ while on placebo (Figure $6 \mathrm{C}$ ), but was abolished while on clonidine (Figure 6D).

\begin{tabular}{|c|c|c|c|c|c|c|}
\hline & \multicolumn{2}{|c|}{$\mathbf{P}_{1}$} & \multicolumn{2}{|c|}{$\mathbf{P}_{2}$} & \multicolumn{2}{|c|}{$\mathbf{P}_{\mathbf{3}}$} \\
\hline & $\mathbf{P}$ & CL & $\mathbf{P}$ & $\mathbf{C L}$ & $\mathbf{P}$ & $\mathbf{C L}$ \\
\hline $\begin{array}{l}\text { Cadence } \\
\text { (step/min) }\end{array}$ & 18.0 & 18.6 & 31.4 & 33.1 & - & 6.5 \\
\hline $\begin{array}{l}\text { Right stride } \\
\text { length }(\mathrm{cm})\end{array}$ & $\begin{array}{c}80.9 \pm \\
7.3\end{array}$ & $\begin{array}{c}79.7 \pm \\
7.0\end{array}$ & $\begin{array}{c}58.9 \pm \\
17.8\end{array}$ & $\begin{array}{c}58.7 \pm \\
14.7\end{array}$ & - & $\begin{array}{c}28.9 \pm \\
6.5\end{array}$ \\
\hline $\begin{array}{l}\text { Left stride } \\
\text { length }(\mathrm{cm})\end{array}$ & $\begin{array}{c}81.1 \pm \\
3.4\end{array}$ & $\begin{array}{c}79.9 \pm \\
2.8\end{array}$ & $\begin{array}{c}64.3 \pm \\
7.5\end{array}$ & $\begin{array}{c}65.8 \pm \\
6.4\end{array}$ & - & $\begin{array}{c}25.7 \pm \\
2.0\end{array}$ \\
\hline
\end{tabular}

Cadence and right and left stride length, of 3 patients $\left(P_{1}, P_{2}\right.$ and $\left.P_{3}\right)$, with the mean and standard deviation displayed for both Placebo and Clonidine administration. 


\section{A PLACEBO}
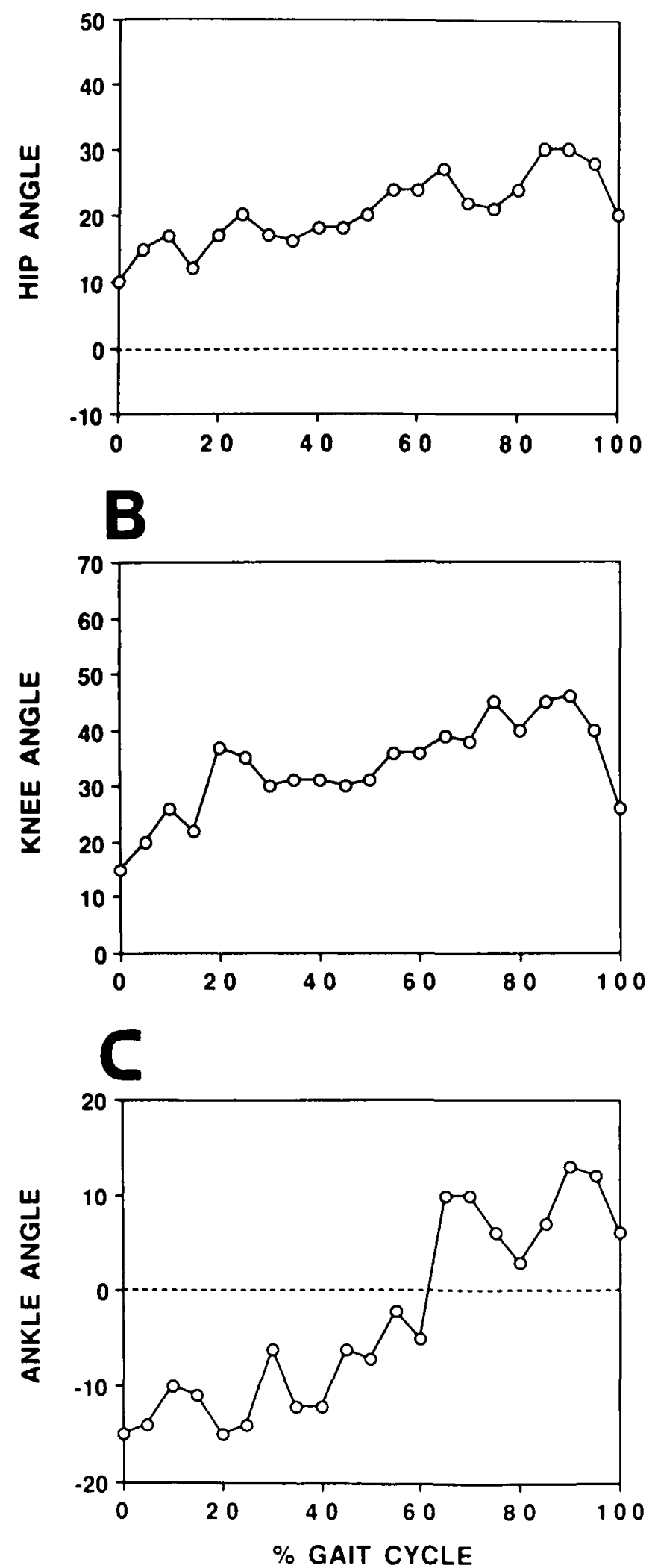

Figure 2 
GM

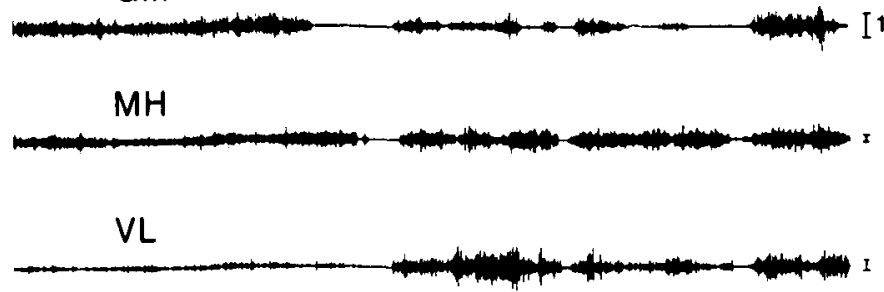

TA

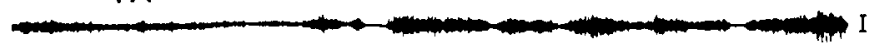

GA
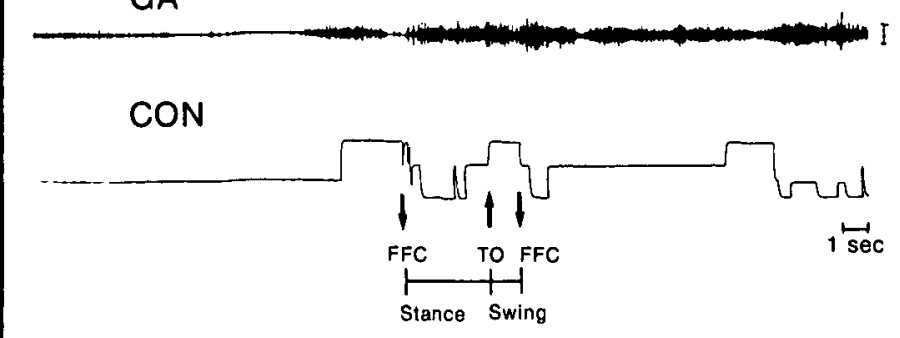

$100 \mu \mathrm{V}$
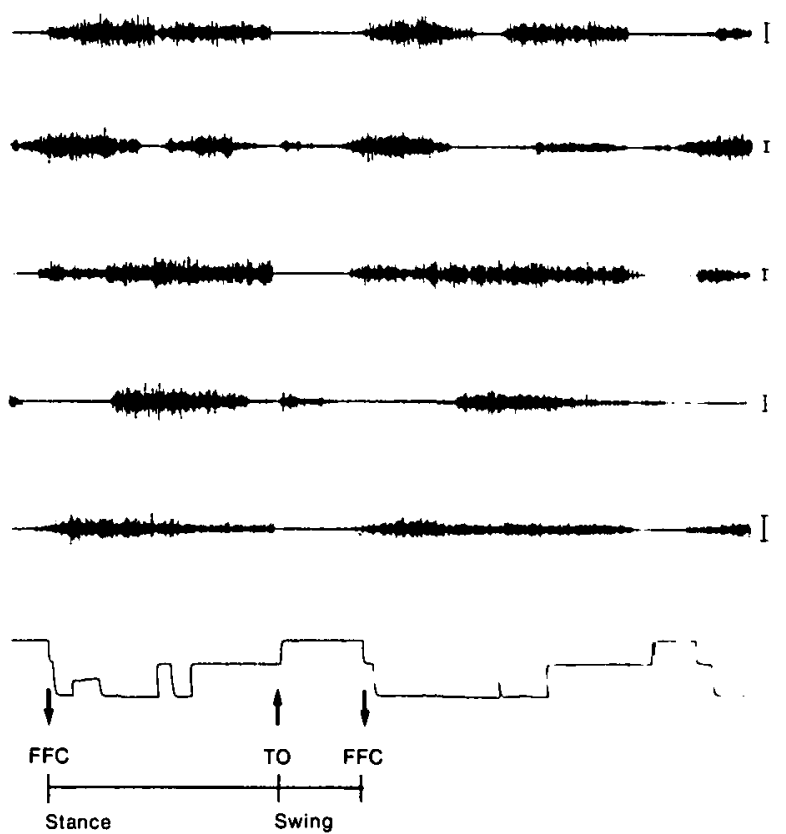

Figure 3-EMG and footswitch recordings of $P_{3}$ walking overground. Note the generalized co-activation of the muscles in the placebo session (left) which is replaced by a more phasic and reciprocal activation pattern in the clonidine session (right). Stance/swing transition occurred at $0.70 \pm$ 0.22 (placebo) and $0.84 \pm 0.07$ (clonidine).

\section{The Effects of Clonidine on Spasticity}

The effects of clonidine on clinical measures of spasticity are summarized in Figure 7. Five out of nine patients showed a reduction in the Tonic Stretch Responses (TSR) with passive knee or ankle movements while 2 out of 9 showed no change or deterioration.

As depicted in Figure 7, 6 of 9 patients showed a marked decrease in the Visual Analog Score (VAS) while on clonidine. Two of the nine patients $\left(P_{2}\right.$ and $\left.P_{6}\right)$ showed minimal changes in their VAS, indicating no change in their perceived spasticity levels across the sessions. One patient $\left(P_{9}\right)$ registered no deterioration between clonidine and placebo.

Evoked ankle clonus (Figure 7) was reduced for 3 out of 9 patients $\left(P_{1}, P_{7}\right.$ and $\left.P_{8}\right)$ on clonidine as compared to the placebo evaluation, but minimal change was shown across sessions for 5 of the 9 patients. Only one patient $\left(P_{2}\right)$ showed increased clonus on clonidine.

In Figure $5 \mathrm{C}$ and $\mathrm{D}$, an example of the effect of clonidine on the tonic stretch reflex is presented. The consistent stretch evoked in the $\mathrm{MH}$ during placebo administration (Figure 5C) was markedly decreased during clonidine for $\mathrm{P}_{4}$ (Figure 5D). The EMG recordings of TA and $\mathrm{GA}$ in $\mathrm{P}_{8}$ during clonus testing

Figure 2 - The hip, knee and ankle joint excursions for the only one gait cycle of $P_{3}$ took during the placebo period as well as a representative gait cycle during clonidine period are presented. Points represent every $5 \%$ of the step cycle. Arrows indicate TO for each gait cycle. Stance/swing transition occurred at $70 \% \pm 22 \%$ (placebo) and $84 \% \pm 7 \%$ (clonidine) of the gait cycle. are presented in Figure $6 \mathrm{C}$ and D. The sustained ankle clonus which was evoked during the placebo session was almost completely abolished with clonidine (Figure 6D).

Among the patients who completed their diaries, half reported a reduction in daily spasms while the other half found no change whether on clonidine or on placebo. The majority of patients noted a reduction in daily clonus, while 1 of the 5 recorded no change with clonidine. No patient reported an increase in the frequency of daily spasms or clonus. In summary, the degree of passively evoked tonic stretch reflexes, the frequency of occurrence of clonus and patients' subjective perception of spasticity tended to decrease during clonidine therapy while evoked ankle clonus was inconsistently affected.

\section{The Side Effects of Clonidine}

Side effects were experienced by 8 of 9 patients during dosage increases, although for most patients these symptoms were transient. The side effects experienced included dryness of the eyes and mouth, lethargy, mild hypotension and constipation. Dryness of the eyes and mouth were the most common. The majority of patients experienced either transient or negligible side-effects; while two patients experienced moderate to severe side effects in response to clonidine therapy (lethargy and constipation).

\section{Discussion}

\section{The Effects of Clonidine on the Locomotor Pattern}

This study represents an initial attempt to elucidate the possible role of clonidine in modulation of locomotion and degree of 


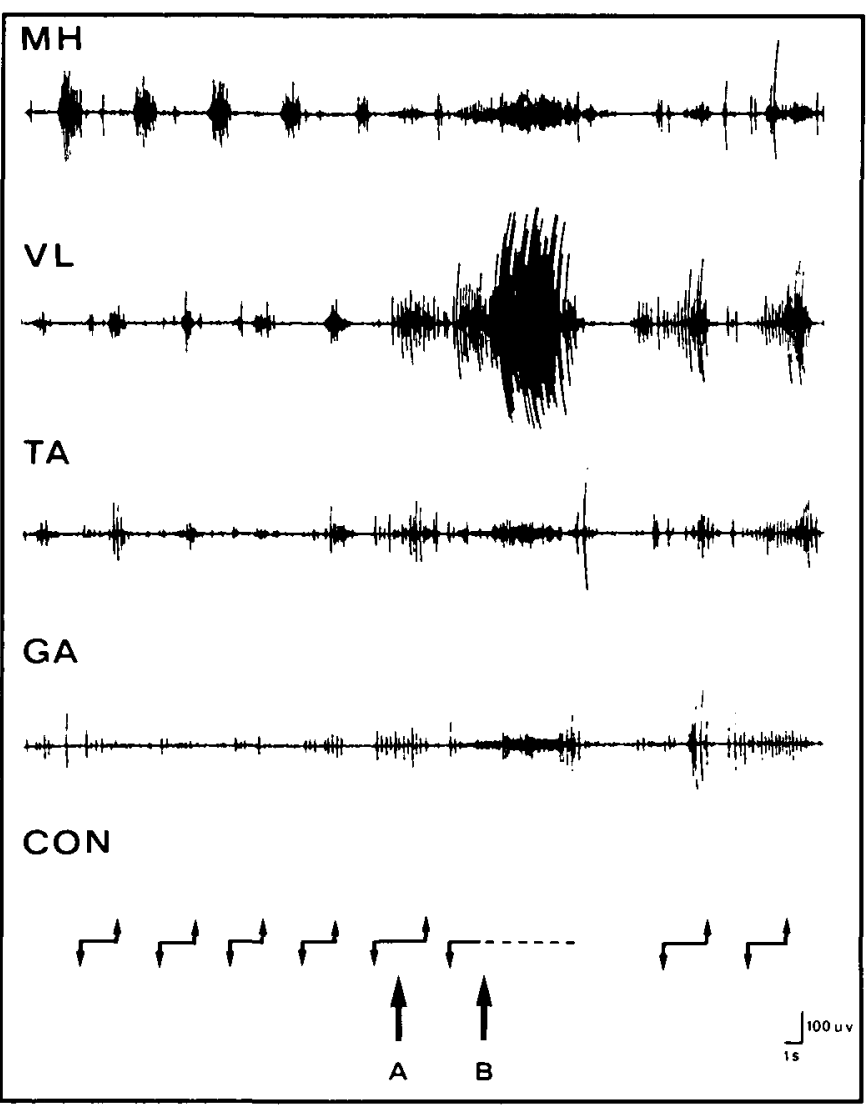

Figure 4-EMG activity in right muscles for paraplegic $P_{8}$ during assisted treadmill locomotion. Downward arrows indicate FFC, upward arrows TO, and horizontal lines reflect stance phase. The single arrow indicates when verbal instructions were given for $P_{8}$ 10 attempt independent stepping with the right foot. The prolonged swing phase in the subsequent step reflects the dragging of his foot, as he was unable to step forward successfully.

spasticity in spinal cord injured humans. In one severely spastic paretic patient, the locomotor pattern was markedly improved such that the patient progressed from being functionally nonambulatory to walking independently with aids. Interestingly, the degree of spasticity measured at rest was minimally affected by clonidine in this patient. This raises the question of whether a reduction in tonic stretch reflexes or clonus measured in resting position is necessarily associated with improvement in functional outcomes such as locomotion. Other studies indicate that baclofen reduces tonic stretch reflexes at rest without major improvement in motor function. ${ }^{22}$ The relative contribution of tonic stretch reflex to locomotion remains controversial. 23,24 Further investigation is needed to clarify this issue.

The contrast between the striking effects on $\mathrm{P}_{3}$ 's overground locomotor performance and the relatively mild changes noted in $P_{1}$ and $P_{2}$ may be related to several factors. $P_{3}$ 's injury was much more recent (1 year post-lesion) than the other two paraparetics $\left(\mathrm{P}_{1}: 2\right.$ yrs., $\mathrm{P}_{2}: 4$ yrs.), and it has been suggested that in the presence of a chronic lesion, physiological changes can occur both centrally and peripherally at the muscular level. ${ }^{26}$ Moreover, $\mathrm{P}_{3}$ received a higher dosage than the other patients and experienced a greater degree of spasticity. $P_{1}$ 's spasticity had already been partially controlled by other medications over the past 2 years. The spasticity measured by $P_{1}$ and $P_{2}$ was definitely less than the other SCI patients.

In contrast to the paretic patients, the paraplegic patients could not walk on the treadmill, either before or following administration of clonidine. This raises again the debate of whether in humans locomotor control is primarily a spinal phenomenon which has been clearly demonstrated in spinal cats. 13,14,26 It has not been possible to elicit treadmill induced stepping in SCI human subjects in two previous studies ${ }^{27,28}$ or in our own study, although a locomotor-like EMG pattern was evoked during manually assisted locomotion. Zomlefer 28 ascribed this to either the action of a spinal stepping generator or to alternating stretch reflexes. Our findings support the latter explanation, as the regular EMG burst activity during assisted locomotion was replaced by a marked tonic activity when assistance was withdrawn, and the EMG burst activity was markedly decreased by clonidine. The absence of the locomotor pattern in complete SCI patients could possibly be explained by the chronic state as they had not experienced locomotion for many years. It is possible that the spinal central pattern generator for locomotion depends more heavily on the presence of supraspinal influences in primates. ${ }^{29,30}$ It is also possible that some forms of flexor reflex afferent stimuli are required to trigger spinal locomotion as demonstrated in spinal cats. ${ }^{31,32}$ It can be argued that a higher dosage of clonidine may be necessary to facilitate the expression of the locomotor pattern, however, the presence of adverse side-effects is an important limiting factor. An alternative method of drug administration, such as intrathecal injection, which would help to minimize side effects, should also be investigated. Finally, another limiting factor was that three patients were taking other drugs such as baclofen at the time of the present study. This could possibly interfere with the effect of clonidine.

\section{The Effects of Clonidine on Spasticity}

A positive relationship between dosage and antispastic effects has previously been reported by Nance et alll and Maynard ${ }^{10}$, with the latter suggesting a therapeutic threshold dose of $0.30 \mathrm{mg} /$ day. In the present study, the greatest reduction in spasticity was in the 0.15 to $0.25 \mathrm{mg} /$ day range and the only patient below $0.15 \mathrm{mg} /$ day experienced no beneficial effects. In future studies, the inclusion of blood-plasma level sampling should be used to monitor the fluctuations of the clonidine level.

While the site of the clonidine action in SCI patients is yet to be determined, animal studies using spinal rats have revealed two possible sites. Low dosages of clonidine $(0.06-0.10$ $\mathrm{mg} / \mathrm{kg}$ ), which had an inhibitory effect on spontaneous EMG activity 33 and tonic reflexive discharges, appeared to act on alpha- 2 receptors. ${ }^{34}$ In contrast, at higher doses $(0.05 \mathrm{mg} / \mathrm{kg})$ clonidine decreased spontaneous EMG activity and even potentiated the tonic reflexive activity, possibly through action at alpha- 1 receptors. 35,36 These hypotheses were supported by the finding that the alpha-2 antagonist yohimbine reversed only the inhibitory effects of clonidine. ${ }^{34}$ In light of these results, further investigation is required to clarify the actual site of clonidine's action. 


\section{PLACEBO}

A

\section{$\mathbf{M H}$}

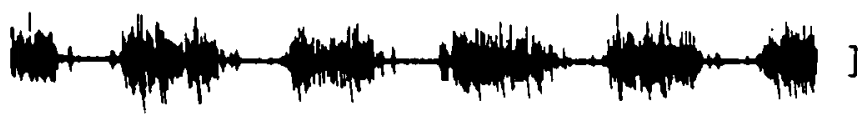

$\mathbf{M H}$

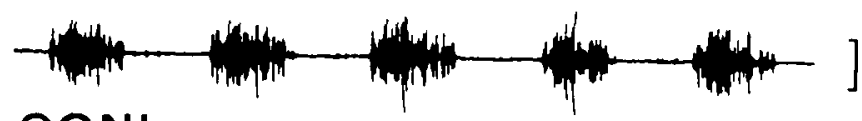

\section{CONL}

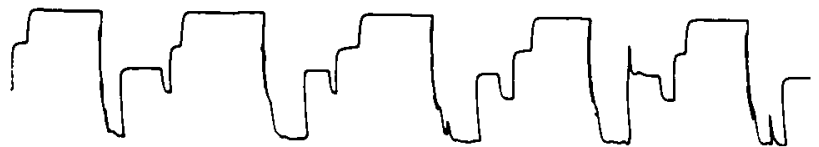

\section{CONR}

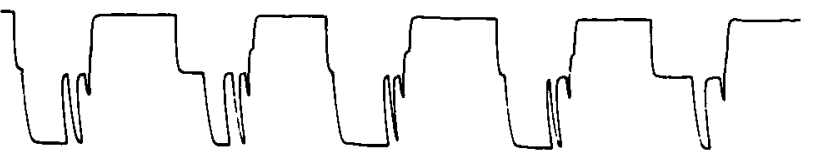

C

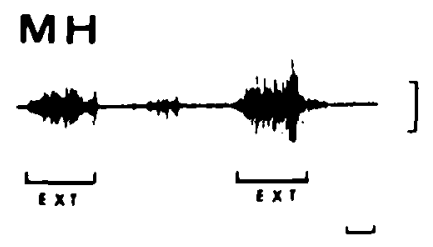

\section{CLONIDINE}

B

\section{$\mathrm{MH}$}

\section{$\mathrm{MH}$}

\section{CONL}

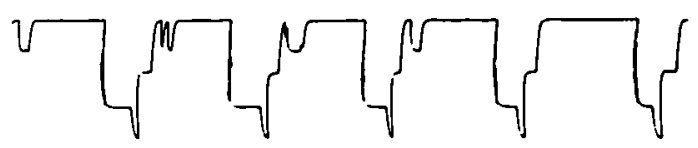

\section{CONR}

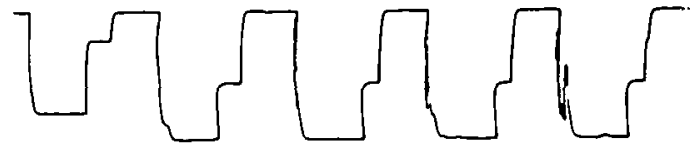

D

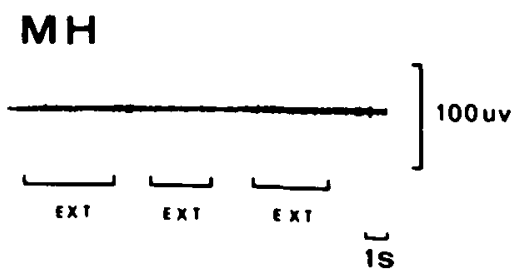

Figure 5-Bilateral MH EMG activity and footswitch traces of paraplegic $P_{6}$ during assisted treadmill locomotion are presented for the placebo (A) and clonidine (B) sessions. Recordings of left $M H$ EMG during passive knee extension for the placebo $(C)$ and clonidine $(D)$ sessions are also presented. The duration of the passive extension was kept constant across the sessions. The vertical calibration indicates I00w' and horizontal calibration indicates 1 second. 


\section{PLACEBO}

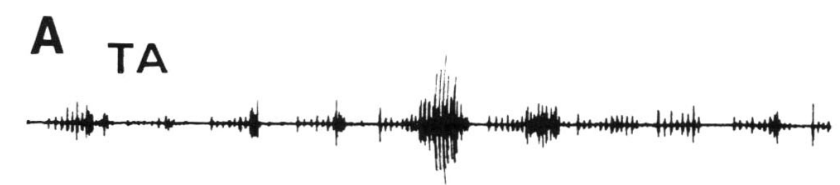

GA

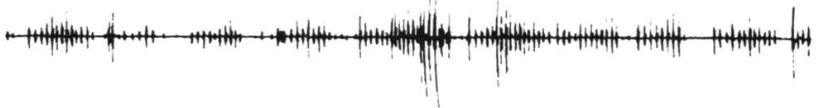

CON

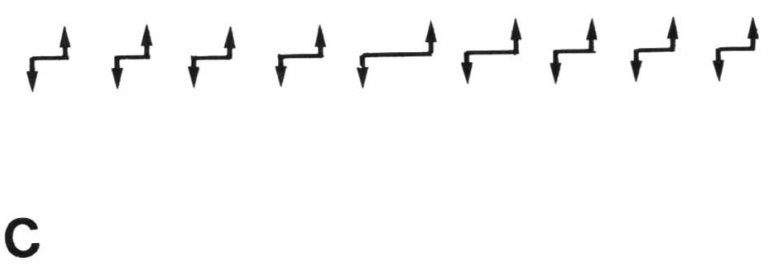

TA

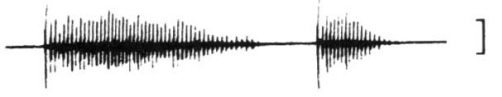

GA

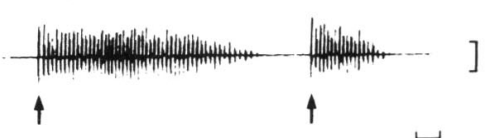

15

\section{CLONIDINE}

B TA

GA

CON

$\vec{t}+\vec{t}+\vec{t}$

D

TA

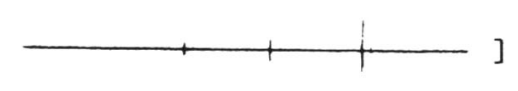

GA

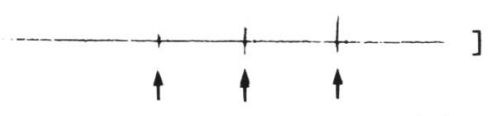

1s

Figure 6-Right TA and GA EMG activity of paraplegic $P_{8}$ during assisted treadmill locomotion are depicted for the placebo (A) and clonidine (B) sessions. Downward arrow's indicate FFC, while upward arrow's indicate TO. Evoked ankle clonus is reflected in the TA and GA EMG activity during passive dorsiflexion (See Arrows) for the placebo $(C)$ and clonidine sessions $(D)$. The vertical calibration indicates 100 uv and horizontal calibration indicates 1 second. 


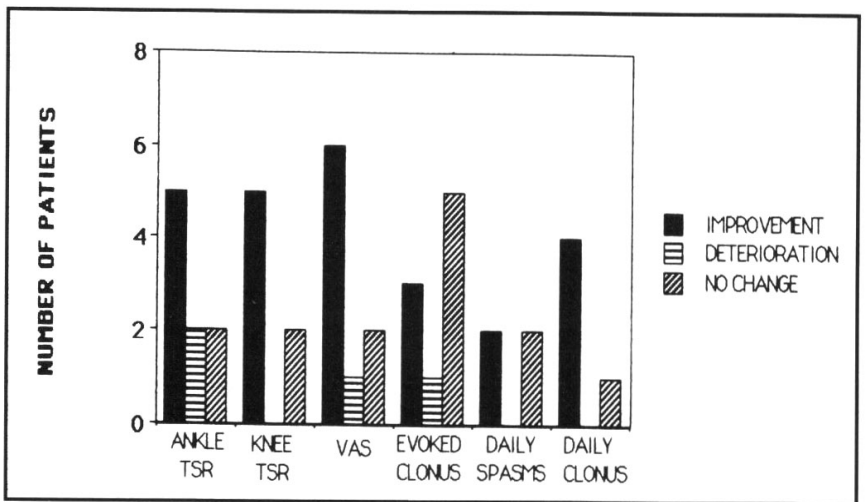

Figure 7 - Comparison of the patient's scores on clinical spasticity tests between the placebo and clonidine sessions $\left(P_{1}:\right.$ pre-medication and clonidine sessions). For the ankle TSR, clonus and VAS measures, all 9 patients are included; for the knee TSR, the 7 patients tested are represented: for the diary of spasms and clonus, the 4 and 5 patients who respectively completed the diaries are presented. Right and left values are combined for the TSR and clonus tests. Improvement implies a reduction of $\geq I$ point, deterioration means an increase of $\geq I$ point.

In summary, this study was a first attempt to investigate the effect of clonidine on locomotor patterns and on spasticity in patients with chronic spinal cord lesions. Within the limited and heterogeneous sample size, it was difficult to draw conclusions about the therapeutic effects of clonidine on both locomotor pattern and on spasticity. Further studies are needed to investigate the important questions raised and to understand the mechanisms of action of clonidine.

\section{AbBreviations}

$\begin{array}{llll}\mathrm{P}_{\mathrm{n}} & \text { Patient } & \mathrm{GM} & \text { Gluteus-Maximus } \\ \mathrm{M} & \text { Male } & \mathrm{MH} & \text { Medial Hamstrings } \\ \mathrm{T} & \text { Thoracic } & \text { VL } & \text { Vastus Lateralis } \\ \mathrm{C} & \text { Cervical } & \text { TA } & \text { Tibialis Anterior } \\ \text { CON } & \text { Footswitch Contact } & \text { GA } & \text { Gastrocnemius } \\ \text { TO } & \text { Toe-off } & \text { FFC } & \text { Foot-Floor Contact }\end{array}$

\section{ACKNOWLEDGEMENTS}

This work was supported by the Medical Research Council of Canada. Medication was provided by Boerhinger Ingelheim Co. $\mathrm{H}$. Barbeau is a research scholar of the Fonds de la recherche en Sauté du Québec. We thank Dr. S. Gauthier and the Montreal Rehabilitation Institute for referring the patients and J. Fung for the helpful comments on the manuscript.

\section{REFERENCES}

1 Knutsson E. Analysis of gait and isokinetic movements for evaluation of antispastic drugs or physical therapies. $I n$ : Desmedt JE, ed. Motor Control Mechanisms in Health and Disease. New York: Raven Press 1983; 1013-1034.

2. Conrad B, Beneke R, Carnehl J, et al. Pathophysiological aspects of human locomotion. I $n$ : Desmedt JE, ed. Advances in Neurology, New York: Raven Press 1983; 717-726.

3. Conrad B, Beneke R, Meinck HM. Gait disturbances in paraspastic patients. In: Delwaide PJ, Young RR, eds. Restorative Neurology, Vol 1. Clinical Neurophysiology in Spasticity. Netherlands: Elsevier Science Publishers BV (Biomedical Division) $1985 ; 155-174$
4. Dietz V. Impaired reflex control of posture and gait in spastic paresis. In: Bles W, Brandt TH, eds. Disorders of Posture and Gait. Netherlands: Elsevier Science Publishers BV (Biomedical Division) 1986; 243-252.,

5. Barbeau H, Fung J, Stewart J, et al. Impairment of spastic paraparetic gait: Implications for new rehabilitation strategies. Proceeding of the fifth biennial conference and human locomotion symposium of the Canadian Society for Biomechanics 1988; 12-16.

6. Chapman $\mathrm{CE}$, Wiesendanger $\mathrm{M}$. The physiological and anatomical basis of spasticity: A review. Physiotherapy Canada 1982; 34: 125-135.

7. Knutsson E, Richards C. Different types of disturbed motor control in gait of hemiparetic patients. Brain 1979; 102: 405-430.

8. Knutsson E. Studies of gait control in patients with spastic paresis. In: Delwaide PJ, Young RR, eds. Clinical Neurophysiology in Spasticity. Netherlands: Elsevier Science Publishers BV (Biomedical Division) 1985; 175-182.

9. Tuckman J, Chu DS, Petrillo CR, et al. Clinical trial of an alpha adrenergic receptor stimulating drug (Clonidine) for the treatment of spasticity in spinal cord injured patients. I $n$ : Naftchi NZE, ed. Spinal Cord Injuries; Spectrum Publications 1983; 133-137.

10. Maynard FM. Early clinical experience with clonidine in spinal spasticity. Paraplegia 1986; 24: 175-192.

11. Nance PW, Shears AH, Nance DM. Clonidine in spinal cord injury. J Can Med Assoc 1985; 133: 41-42.

12. Rossignol S, Barbeau $H$, Julien $C$. Locomotion of the adult chronic spinal cat and its modifications by monoaminergic agonists and antagonists. In: Goldberger ME, Gorio A, and Murray M, eds. Development and Plasticity of the Mammalian Spinal Cord. Fidia Research Series, Vol III. Padova: Liviana Press. 1986; 323345.

13. Barbeau $\mathrm{H}$, Julien $\mathrm{C}$, Rossignol $\mathrm{S}$. The effects of clonidine and yohimbine on locomotion and cutaneous reflexes in the adult spinal cat. Brain Res 1987; 437: 83-96.

14. Forssberg $\mathrm{H}$, Grillner $\mathrm{S}$. The locomotion of the acute spinal cat injected with Clonidine iv. Brain Res 1973; 50: 184-186.

15. Barbeau H, Rossignol S. Effects of noradrenergic, serotonergic and dopaminergic drugs on the initiation of locomotion in the adult spinal cat. Neurosci Abst 1989; 15:393.

16. Grillner $S$. Control of locomotion in bipeds, tetrapods, and fish. $I n$ : Brooks VB, ed. The Nervous System: Motor Control. Handbook of Physiology, Section 1. Amer Physiol Soc Maryland: Waverly Press 1981; 1179-1236.

17. Stewart JE, Barbeau H, Gauthier S. The effects of clonidine on clinical spasticity and on the modulation of the locomotor pattern in chronic spastic spinal cord patients. Neurosci Abst 1987; 13: 353 .

18. Frankel HL, Hancock DO, Hyslop G, et al. The value of postural reduction in the initial management of closed injuries of the spine with paraplegia and tetraplegia. Paraplegia 1967; 7: 179192.

19. Arndts D, Doevendans J, Kirsten R, et al. New aspects of the pharmacokinetics and pharmacodynamics of clonidine in man. Eur $\mathrm{J}$ Clin Pharmacol 1983; 24: 21-30.

20. Anavekar N, Jarott B, Toscano M, et al. Pharmacokinetics and pharmacodynamic studies of oral clonidine in normotensive subjects. Eur J Clin Pharmacol 1982; 23: 1-5.

21. Barbeau $H$, Wainberg $M$, Finch L. Description and application of a system for locomotor rehabilitation. Med Biol Eng Comp 1987; 25: 341-344.

22. McLellan DL. Co-contraction and stretch reflexes in spasticity during treatment with baclofen. J Neurol Neurosurg Psychiatry 1977; 40: 30-38.

23. Landau WM. Spasticity - What is it? What is it not? In: Feldman RG, Young RR and Koella WP, eds. Spasticity: Disordered Motor Control, Chicago Yearbook 1980; 17-24.

24. Knutsson E, Mårtensson A. Dynamic motor capacity in spastic paresis and its relation to prime motor dysfunction, spastic reflexes and antagonist coactivation. Scand J Rehab Med 1980; 138: 1-14. 
25. Dietz V, Berger W. Normal and impaired regulation of muscle stiffness in gait: A new hypothesis about hypertonia. Exp Neurol 1983; 79: 680-687.

26. Grillner $S$, Zangger $P$. On the central generation of locomotion in the low spinal cat. Exp Brain Res 1979; 34: 241-261.

27. Eidelberg, E. Consequences of spinal cord lesions upon motor function, with special reference to locomotor activity. Prog Neurobiology 1981; 17: 135-202.

28. Zomlefer MR, Gaines RF, McCleary LG. Locomotor control in spinal cord injured humans. Neuroscience Abst 1986; 188.2: 634.

29. Eidelberg E, Walsen JG, Nguyen LH. Locomotor control in macaque monkeys. Brain 1981; 104: 647-663.

30. Vilensky AJ. Locomotor behavior and control in human and nonhuman primates: Comparisons with cats and dogs. Neurosci Biobehav Rev 1987; 11:263-274.

31. Forssberg H. Stumbling corrective reaction: A phase-dependent compensatory reaction during locomotion. J Neurophysiol 1979; 42: 936-953.
32. Forssberg H. Phasic gating of cutaneous reflexes during locomotion. In: Taylor A, Prochazka A, eds. Muscle receptors and movement. London, (MacMillan) 1981; 403-412.

33. Tremblay LE, Bédard P. Effect of clonidine on motoneuron excitability in spinalized rats. Neuropharmacology 1986; $25: 41$ 46.

34. Kawasaki K, Takesu H, Matsushita AS. Modulation of spinal reflex activities in acute spinal rats with alpha-adrenergic agonists and antagonists. Jap J Pharmacol 1978; 28: 165-168.

35. Kehne J, Gallager DW, Davis M. Spinalization unmasks clonidine's alpha- 1 adrenergic mediated excitation of the flexor reflex in rats. J Neurosci 1985; 5: 1583-1590.

36. Yaksh T. Pharmacology of spinal adrenergic systems which modulate spinal nociceptive processing. Pharmacol Biochem Behav 1985; $22: 845-858$. 